\title{
Calculating the surface melt rate of Antarctic glaciers using satellite derived temperatures and stream flows
}

\section{Lars Brabyn $^{1}$ and Glen Stichbury \\ ${ }^{1}$ Corresponding author: larsb@waikato.ac.nz, Geography Programme, University of Waikato}

\begin{abstract}
Melt rate models are fundamental for understanding the impacts of climate change on glaciers and the subsequent effects on habitats and sea level rise. Ice melt models have mostly been derived from energy balance or air temperature index calculations. This research demonstrates that satellite derived land surface temperature (LST) measurements provide a simpler method for estimating surface melt rate that substitutes for energy balance models. Since these satellite images are continuous (distributed) across space, they do not need calibration for topography. Antarctic glacier melt discharge data from nearby stream gauges were used to calibrate a LST derived melt model. The model calculations are simplified by the fact that groundwater flow is assumed to be minimal due to permafrost, and the glaciers are assumed to only melt on the surface. A new method called the Temperature Area Sum model is developed, which builds on an existing Temperature Area Index model. A daily melt rate model is developed using 77 Landsat 8 images and calculates the volume of meltwater produced per hectare for any given LST between $-7^{0} \mathrm{C}$ and $0^{0} \mathrm{C}$. A seasonal average daily melt rate model is also developed that uses 1660 MODIS images. The utility of the seasonal MODIS model is demonstrated by calculating melt rates, water flows, and wetness across the entire Ross Sea region. An unexpected large wet area to the southwest of the Ross Ice Shelf requires further investigation and demonstrates the usefulness of these models for large remote areas. Surface melt rate and wetness can now be calculated for different climate change scenarios.
\end{abstract}

Keywords: Antarctic Glaciers; Landsat; Land Surface Temperature; Melt Rate; MODIS 


\section{Declarations}

\section{Funding}

This research was funded by the Ministry of Business, Innovation and Employment, New Zealand, through contract number CO9X1413.

\section{Conflicts of interest/Competing interests}

Not applicable

\section{Ethics approval}

This research did not involve research of human subjects or animals, therefore ethical approval was not required.

\section{Consent to participate}

Not applicable

\section{Consent for publication}

The authors consent to this research article being published

\section{Availability of data and material}

The data is not available

\section{Code availability}

The code is not available

\section{Authors' contributions}

Both authors contributed equally to the original concept of the research, the analysis, and the writing.

\section{Acknowledgments}


This researched used stream flow data collected through the McMurdo Dry Valleys Long Term Ecological Research programme. We acknowledge the considerable effort that this involved and the benefits of this data set for our research. We also acknowledge the logistical support provided by Antarctic New Zealand, which enabled us to complete field visits and better understand the McMurdo Dry Valleys environment. Importantly, this research was part of the Ross Sea Region Terrestrial Data Analysis research program, which was funded by the Ministry of Business, Innovation and Employment, New Zealand, through contract number CO9X1413. 


\section{Introduction}

Understanding ice melt rates in relation to temperature is highly relevant given the predicted climate change scenarios and the fact that ice is a significant part of the physical geography of planet earth. At the global scale, ice melt from the major ice caps on earth are predicted to contribute significantly to sea level rise. At the habitat and ecosystem scale, ice melt could significantly change the availability of liquid water in alpine and polar regions. Given that liquid freshwater is a requirement for terrestrial biology and the scarcity of water limits biological activity, a change in the availability of liquid water will change habitats and ecosystems (Adiguzel et al 2019).

Antarctica is considered the driest continent because of the sub-zero temperatures, and the scarcity of liquid water limits biological activity (Fountain et al, 1999; Gooseff et al, 2003; Kennedy, 1993). If ice melt increases, Antarctica may no longer be considered a desert and the biology of the region will change accordingly. Meltwater from ice caps also changes the salinity of seawater, which impacts on the freezing point of sea water, the formation and extent of sea ice, and the resulting feedback mechanisms for climate change.

This paper focuses solely on surface melt of glaciers on land, which in continental Antarctica is considered to be the dominant form of melting for these glaciers. Sea temperature is a significant factor for the melting and stability of floating glaciers (ice shelfs) (Etourneau, 2019), however, this is outside the scope of this paper. The melting of glaciers on land is assumed to be restricted to the near surface because of the year-round subfreezing temperatures restrict hydraulic systems from developing (Dana, et al. 2002) and geothermal melting of glaciers is negligible. This is not the case with many temperate glaciers. Our research does not take into account basal melting from the ambient geothermal gradient as this is considered insignificant for the glaciers being studied.

The surface melt rate of glaciers in relation to temperature is difficult to calculate because stream gauges need to be located near glaciers and monitored regularly. Also, for most temperate glaciers around the world, a high proportion of glacier melt seeps into the groundwater and is not captured by stream gauges. For this reason, temperature index models of melt rate are calibrated specifically for particular catchments, usually using regression models that compensate for groundwater flow.

The McMurdo Dry Valleys in Antarctica, provide an opportunity to calculate surface melt rates of glaciers because there are seven stream gauges that have been maintained regularly 
over the last decade, and groundwater flow can be assumed to be insignificant because of permafrost (Chinn and Mason, 2015). Kingslake et al. (2017) have used visual interpretation of Landsat satellite images so show that there are many interconnected streams and ponds on Antarctica's ice shelves resulting from surface meltwater. They also note that the “accumulation of locally derived meltwater has triggered ice-shelf collapse in Antarctica’s warmest regions” (p.352).

Not surprisingly, there is a wealth of research on calculating surface melt rates of glaciers. Excluding research that calculates changes in the extent or surface mass balance of glaciers (Costi et al. 2018), there are two dominant glacier surface melt modelling methods - energy balance and temperature index (Hock, 2005). Energy balance modelling assesses the energy fluxes to and from the surface. These models rely on in situ energy budget measurements and are generally limited in spatial and temporal extent (Hock, 2005). Examples from the McMurdo Dry Valleys include Hoffman et al, (2008, 2014, 2016); Lewis et al (1998); and MacDonell et al, (2013). The simpler and more widely used temperature index model utilises air temperature as a sole index for melt energy (Braithwaite, 1995; Hock, 2003, Barrand, 2013)). McMurdo Dry Valley examples include Dana et al (2002) and Ebnet et al (2005). Temperature index modelling generally relies on air temperature readings from weather stations located in the vicinity of glaciers and requires spatial modelling to compensate for aspect, elevation, and albedo. Positive degree days is the temperature metric commonly used.

This research uses land surface thermal infra-red (IR) sensors aboard satellites which are a better alternative to air temperature based on weather stations. Satellite thermal IR images provide spatial and temporal variation of land surface temperature (LST) at a variety of scales. For example, Landsat 8 captures thermal IR for most parts of earth using $60 \mathrm{~m}$ pixels every 16 days, and MODIS captures thermal IR daily but using 1000m pixels. LST measured by satellites represent the balance of energy fluxes above and below the earth's surface. These LST measurements are distributed continuously across space and are "ready to use" measurements that do not require spatial extrapolation and modelling of point-based weather station data. These measurements take into account elevation, aspect, sun angle, and albedo; therefore additional modelling for these factors is not required. For this reason, satellite based LST are much simpler and more accurate than air temperature for modelling glacier melt.

The only prior comparable study that uses satellite LST to model glacier melt in the McMurdo Dry Valleys was completed by Dana et al. (2002). The main focus of their study 
was the analysis of LST from six AVHRR images for a single day to determine if there was a relationship between LST of Taylor Valley glaciers and the corresponding stream discharge data. They concluded that satellite data had a strong relationship with diurnal stream flows. The core measurement that was derived from AVHRR images was the Temperature Area Index (TAI), which they defined as the number of pixels at or above a specified temperature. The TAI is a variation of the positive degree day measurement, and it is important that area (in this case pixel count) is included in the metric because glacier size has a significant influence on water discharge. In the Dana et al (2002) study, OLS regression models were used to determine the relationship between the TAI and stream flow data. The strength of the model is based on the $r^{2}$ value of the regression. The best relationship with stream flow was when the temperature threshold was minus $7^{\circ} \mathrm{C}$. This threshold might seem unusual but the surface temperature of glaciers is rarely above zero. If surface of glaciers were above zero, there would be considerable pooling of meltwater and it would be the meltwater that is above zero not the glacial ice. If the threshold is close to zero then many pixels that are producing meltwater will be excluded. As the temperature threshold increases towards $0^{\circ} \mathrm{C}$, the number of pixels at or above the given temperature threshold approaches zero, and many pixels that are producing meltwater will be excluded. If the threshold is too low, pixels that are unlikely to produce water are included.

We build on the Dana et al (2002) research by developing an alternative degree-day metric that we call the Temperature Area Sum (TAS). Rather than counting the number of pixels above a threshold, the difference between the threshold and pixel temperature is calculated for each pixel and this is summed for the particular glacier. To build a robust model, we use 77 cloud free Landsat images collected between 2013 and 2015 to produce a melt rate regression model based on daily LST changes. We also develop a seasonal melt rate model based on 1660 MODIS images collected between 2002 and 2016. A major difference between Landsat and MODIS is the pixel size (60m versus $1000 \mathrm{~m}$ respectively) and the frequency of the image capture. The larger cell size of MODIS makes it easier to work with but the disadvantage is the spatial precision. We use the Landsat 8 infra-red band to build a model showing the melt rate per hectare for a given LST (Daily Average Discharge L/sec/ha $=0.1$ times surface temperature in Celsius +0.7 ). While the MODIS LST data are used to build a seasonal average daily melt rate model, which is more conducive to the larger pixel size because of the number of images needed. A season-wide model can also include water flow data that has lag time because of the distance between glaciers and flow gauges. 
The goal of this research was to produce a melt rate model that links temperature change to melt rate, and to use this model to enhance the wetness index model developed by Stichbury et al (2011) and apply this to the whole of the Ross Sea region. The original wetness index model provided a relative wetness of different areas, which was calculated using the GIS terrain functions that calculate flow directions and flow accumulation. For calculating flow accumulation, each pixel was weighted by the number of days under snow. Areas under permanent snow were given equal weighting, so the accumulation results were only a relative index rather than actual water flows. The wetness index also includes slope, as water ponds in flat areas and therefore these areas tend to be wetter. With the development of a spatial model of melt rate, the actual water flow accumulations can be calculated. The melt rates were used to weight each pixel so that the actual water flow accumulations were predicted. Since the resulting wetness model incorporates surface temperature, different climate change scenarios that affect surface temperature can be modelled. The result is a spatial model of water availability across the whole of the Ross Sea region that can be used to predict areas of biology activity as well as future biology areas under different climate change scenarios. The rest of this paper describes in more detail the development of a melt rate model and the application of this melt rate to produce an enhanced wetness model.

\section{Materials and methods}

\section{Study Area}

Seven stream gauges were used to determine runoff from the glaciers (Figure 1). These consist of six gauges in the Taylor Valley located on streams flowing from the Commonwealth Glacier, Canada Glacier, Rhone Glacier, Howard Glacier, Crescent Glacier and an unnamed glacier to the immediate east of Crescent Glacier. The seventh gauge is on the Onyx River in the Wright Valley. These valleys are part of what is known as the McMurdo Dry Valleys of Victoria Land, Antarctica, and are the continent's largest expanse of ice-free polar desert. The Dry Valleys consist of bedrock and sandy, gravelly soils with glaciers extending into the valleys from the surrounding mountains. They have a mean annual air temperature of $-18^{\circ} \mathrm{C}$ and $<10 \mathrm{~cm}$ water equivalent annual precipitation (Gooseff, McKnight, Doran, Fountain, \& Lyons, 2011, Chinn, 1981). Lakes and ponds, often perennially ice-covered, are located throughout the valleys as well as ephemeral streams that flow for up to ten weeks during the austral summer (McKnight et al., 1999). 


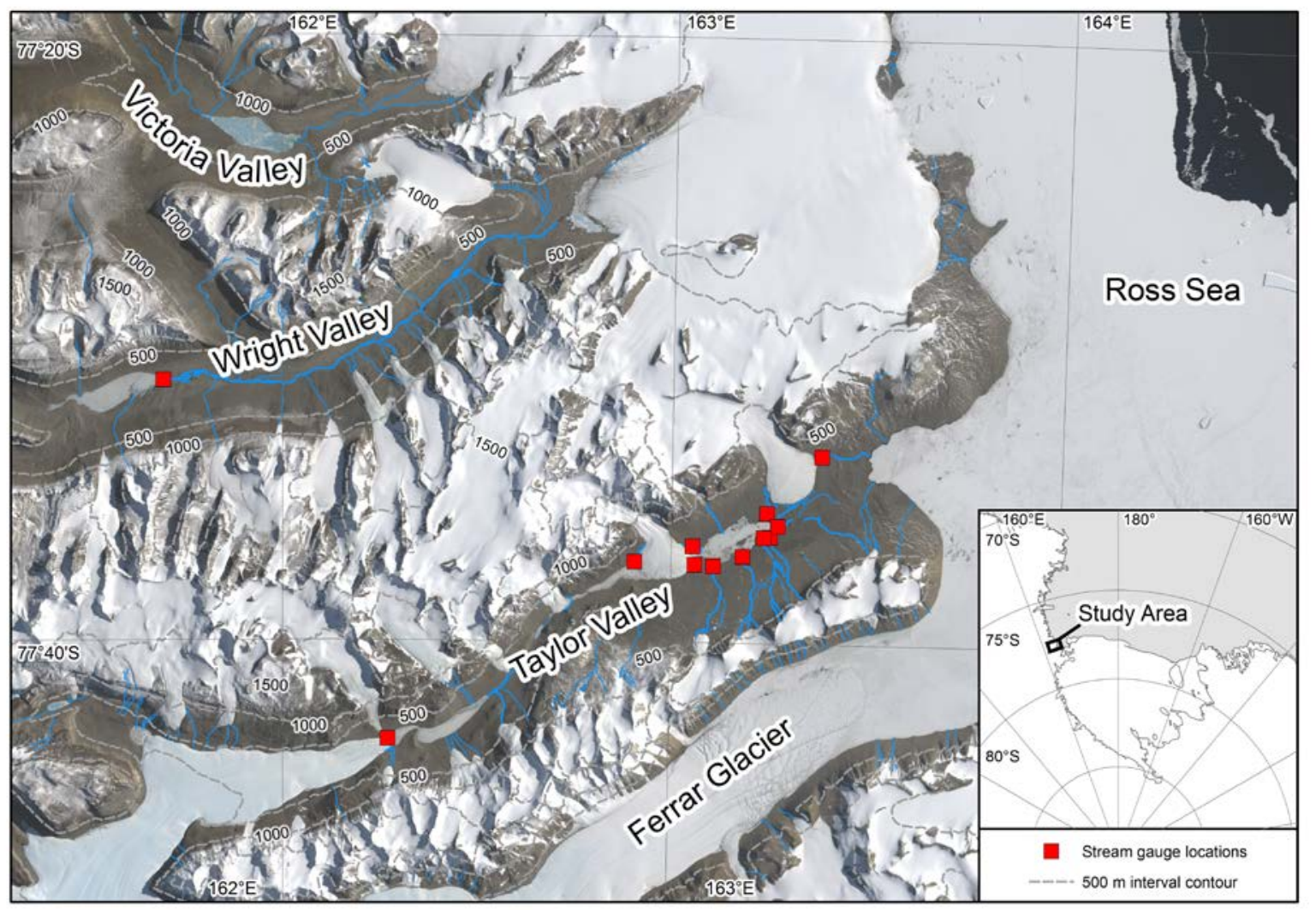

\section{Figure 1. Location of stream gauges and glaciers- Dry Valleys}

Catchment boundaries of the glaciers contributing to each stream gauge were identified using the glacier boundary GIS data from McMurdo Dry Valleys Long Term Ecological Research (2019) project. These boundaries were further refined by using flow accumulation algorithms in ArcGIS. Figure 2 shows the extent of these catchments for analysing the MODIS images. The glaciers in Wright Valley were combined as a single zone for analysis and the Taylor Valley glaciers were analysed individually. For the analysis of Landsat LST, an elevation limit of 1500m was used because this has been recognised as the upper limit of melting (Chinn, 1981). This also reduced the number of computations required. 


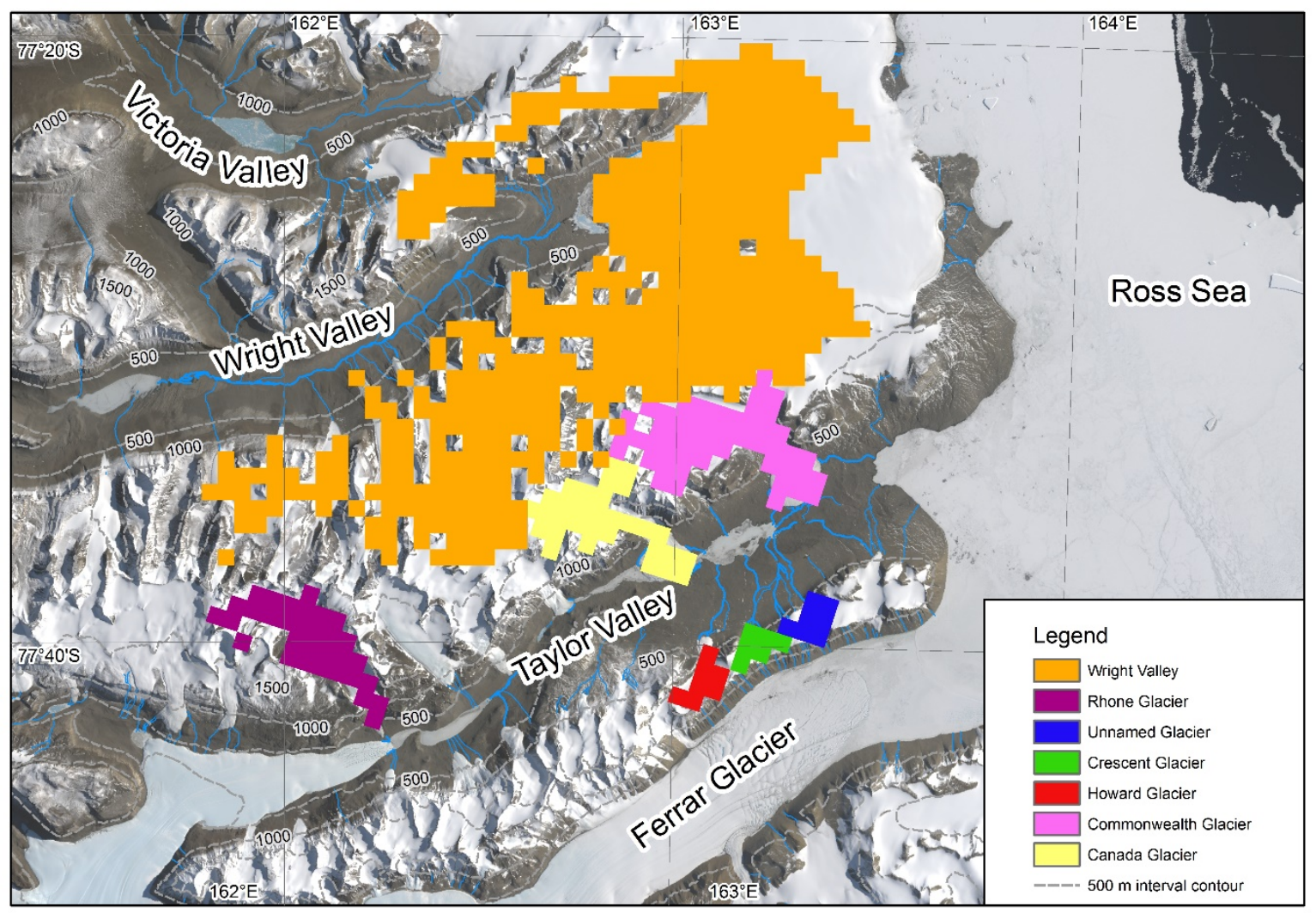

Figure 2. Glaciers catchment zones used for calibrating the MODIS melt rate model

\section{Discharge data}

Stream discharge data for Taylor and Wright Valleys have been collected and maintained by the McMurdo Long-term Ecological Research Program in 15-minute intervals and have been made available as daily average discharge over various periods since 1990 (www.mcmlter.org). The data for the selected glaciers were downloaded and the daily averages summed.

\section{LST derived from satellite thermal infra-red}

Landsat 8 OLI (Operational Land Imager) and TIRS (Thermal Infrared Sensor) Level 1T data of the study area were downloaded from the U.S. Geological Survey's (USGS) Long Term Archive (LTA) using the USGS EarthExplorer. A total of 77 Landsat 8 images were used for this study. These images were cloud-free, and captured for the 2013-2015 study period. The time of the day that Landsat 8 passed over the study site varies but is usually around 9:20am (New Zealand Daylight Time). Only images captured after 9:00am were used. Where glacial zones were captured more than once in a day, the image closest to 9:00am was used. The impact of time of image capture on the model is discussed in the conclusion. 
Python scripting language incorporating ESRI's ArcGIS arcpy site package was utilised to process the Landsat data. The thermal infra-red band 10 of each images was converted to top of atmosphere brightness temperature in Kelvins using the conversion formula provided in the Landsat 8 Data Users’ Handbook.

LST data collected by the Moderate Resolution Imaging Spectroradiometer (MODIS) aboard NASA's Terra and Aqua satellites were also downloaded, which consisted of the average of the daytime temperatures from both satellites. A total of 1660 images were downloaded capturing the surface temperatures between November and February for the years 2002 to 2016.

The Temperature Area Index (TAI) and Temperature Area Sum (TAS) were calculated for each zone in whole degree increments from -12 to $0{ }^{\circ} \mathrm{C}$ :

$$
\begin{aligned}
& T A I=\sum_{j=i}^{\# p i x e l s} I_{j} \begin{cases}I_{i}=0, & T_{j}<R \\
I_{j}=1, & T_{j}>R\end{cases} \\
& T A S=\sum_{j=i}^{\text {\#pixels }} I_{j}\left\{\begin{array}{cc}
I_{i}=0, & T_{j}<R \\
I_{j}=T_{j}-R, & T_{j}>R
\end{array}\right.
\end{aligned}
$$

where $T$ is the pixel brightness temperature and $R$ is the temperature threshold value. (Even though Dana et al's (2002) found that minus $7^{\circ} \mathrm{C}$ threshold produced the best model, we still tested from minus $12^{\circ} \mathrm{C}$ to $0{ }^{\circ} \mathrm{C}$ ).

For the MODIS seasonal melt rate model development, seasonal mean daily discharge and seasonal average daily mean TAI and TAS were calculated by combining by the austral summer season for both the two main months of melt, December and January, and for a more complete season, November to February.

Ordinary Least Squares (OLS) regressions were used to model the relationship for both TAI and TAS models with meltwater discharge. Logarithmic and non-logarithmic data scaling were compared for predictive strength using $\mathrm{r}^{2}$.

Wetness modelling across the Ross Sea Region.

As described in the introduction, a melt rate model based on LST can be used to map flow accumulations across the whole of the Ross Sea Region, which can then be used to map wetness (see Stichbury et al, 2011). The mean daily surface temperature for December and 
January were derived from 2002 to 2016 MODIS images. The best melt model from the above research was then used to determine the quantity of meltwater produced from each MODIS snow pixel. Using the Radarsat Antarctic Mapping Project (RAMP) elevation data, the ArcGIS flow accumulation function showed where this water flows and the accumulation volume. The compound topographic index (CTI) (see Stichbury et al, 2011) was then used to convert this flow accumulation into a wetness index map.

The overall formula for the CTI can be shown as:

$$
\mathrm{CTI}=\ln (a / \tan \beta)
$$

Where $a=$ flow accumulation and $\beta$ is the slope expressed in radians.

\section{Results and Discussion}

\section{Landsat daily model}

Tables 1 and 2 show the regression results between daily discharge and TAI and TAS, respectively. These results show for all glaciers combined as well as individual glaciers. Only $r^{2}$ values for temperature thresholds between $-10^{\circ} \mathrm{C}$ and $-3^{\circ} \mathrm{C}$ are shown because these proved to be the most explanatory. There was no noticeable improvement using data on a logarithmic scale, therefore these results are not shown.

The TAS was a slightly higher predictor of meltwater discharge than TAI, indicating a slight improvement on method. For all glaciers combined, the highest $r^{2}$ value was 0.804 for the TAI model and 0.818 for the TAS model. Interestingly the temperature thresholds used for these models were $-6^{\circ} \mathrm{C}$ and $-7^{\circ} \mathrm{C}$, respectively. This study is therefore consistent with Dana et al (2002). Individually, most glaciers showed strong relationships, but the temperature threshold at which they indicated greatest strength varied.

Table 1: TAI against mean daily discharge rate $\mathbf{r}^{2}$ values by glacial zones.

\begin{tabular}{|c|c|c|c|c|c|c|c|c|}
\hline \multirow[b]{2}{*}{ Glacier } & \multicolumn{8}{|c|}{ Temperature Threshold ${ }^{\circ} \mathrm{C}$} \\
\hline & -10 & -9 & -8 & -7 & -6 & -5 & -4 & -3 \\
\hline All Glaciers & $0.678 * *$ & $0.674 * *$ & $0.739 * *$ & $0.791^{* *}$ & $0.804 * *$ & $0.762 * *$ & $0.777 * *$ & $0.677 * *$ \\
\hline Canada Glacier & $0.72 * *$ & $0.713 * *$ & $0.729 * *$ & $0.763 * *$ & $0.802 * *$ & $0.764 * *$ & $0.81 * *$ & $0.737 * *$ \\
\hline Commonwealth Glacier & $0.766 *$ & $0.753^{*}$ & $0.808 *$ & $0.859 * *$ & $0.863 * *$ & $0.836 *$ & $0.825 *$ & $0.723 *$ \\
\hline Crescent Glacier & $0.915 * *$ & $0.919 * *$ & $0.93^{* *}$ & $0.907 * *$ & $0.81 * *$ & $0.639 *$ & $0.474^{*}$ & 0.433 \\
\hline Howard Glacier & 0.526 & $0.706^{*}$ & $0.779 *$ & $0.757^{*}$ & $0.722 *$ & $0.726^{*}$ & $0.729 *$ & 0.647 \\
\hline Rhone Glacier & $0.755^{* *}$ & $0.754 * *$ & $0.756^{* *}$ & $0.769 * *$ & $0.75^{* *}$ & $0.715 * *$ & $0.662 * *$ & $0.643 * *$ \\
\hline Unnamed Glacier & $0.759 *$ & $0.845^{*}$ & $0.893^{* *}$ & $0.885 * *$ & $0.801 *$ & 0.606 & 0.42 & 0.407 \\
\hline
\end{tabular}

Bold indicates $\mathrm{r}^{2}$ greater than 0.8 , ** indicates $\mathrm{p}<0.001$ and $*$ indicates $\mathrm{p}<0.01$ 
Table 2: TAS against mean daily discharge rate $\mathbf{r}^{2}$ values by glacial zones.

\begin{tabular}{|c|c|c|c|c|c|c|c|c|}
\hline \multirow[b]{2}{*}{ Glacier } & \multicolumn{8}{|c|}{ Temperature Threshold ${ }^{\circ} \mathrm{C}$} \\
\hline & -10 & -9 & -8 & -7 & -6 & -5 & -4 & -3 \\
\hline All Glaciers & $0.769 * *$ & $0.791^{* *}$ & $0.811 * *$ & $0.818 * *$ & $0.808 * *$ & $0.791 * *$ & $0.763^{* *}$ & $0.763 * *$ \\
\hline Canada Glacier & $0.788 * *$ & $0.802 * *$ & $0.82 * *$ & $0.836 * *$ & $0.843 * *$ & $0.83 * *$ & $0.791 * *$ & $0.816 * *$ \\
\hline Commonwealth Glacier & $0.816^{*}$ & $0.835^{*}$ & $0.856 * *$ & $0.862 * *$ & $0.845^{*}$ & $0.829 *$ & $0.82 *$ & 0.843* \\
\hline Crescent Glacier & $0.935 * *$ & $0.921 * *$ & $0.881 * *$ & $0.796 * *$ & $0.678 * *$ & $0.537^{*}$ & 0.452 & 0.381 \\
\hline Howard Glacier & $0.714^{*}$ & $0.767^{*}$ & $0.77 *$ & $0.763^{*}$ & $0.756^{*}$ & $0.749 *$ & $0.7^{*}$ & 0.66 \\
\hline Rhone Glacier & $0.763 * *$ & $0.758 * *$ & $0.752 * *$ & $0.738 * *$ & $0.714^{* *}$ & $0.686 * *$ & $0.662 * *$ & $0.621 * *$ \\
\hline Unnamed Glacier & $0.866 * *$ & $0.889 * *$ & $0.867 * *$ & $0.797 *$ & 0.668 & 0.49 & 0.412 & 0.407 \\
\hline
\end{tabular}

Bold indicates $\mathrm{r}^{2}$ greater than $0.8, * *$ indicates $\mathrm{p}<0.001$ and $*$ indicates $\mathrm{p}<0.01$ for high $\mathrm{r}^{2}$ values

Figure 3 graphs the values used for the TAS calculation with $-7^{\circ} \mathrm{C}$ threshold and the OLS model used. The y intercept is forced to zero because at $-7^{\circ} \mathrm{C}$ there is unlikely to be meltwater. Without forced zero the y intercept is $22 \mathrm{~L} / \mathrm{sec}$ and the $\mathrm{r}^{2}$ is 0.818 (same as in Table 2). There are many low values used in this model and the coefficient (0.009) is mostly determined by the values from the Commonwealth and Canada glaciers.

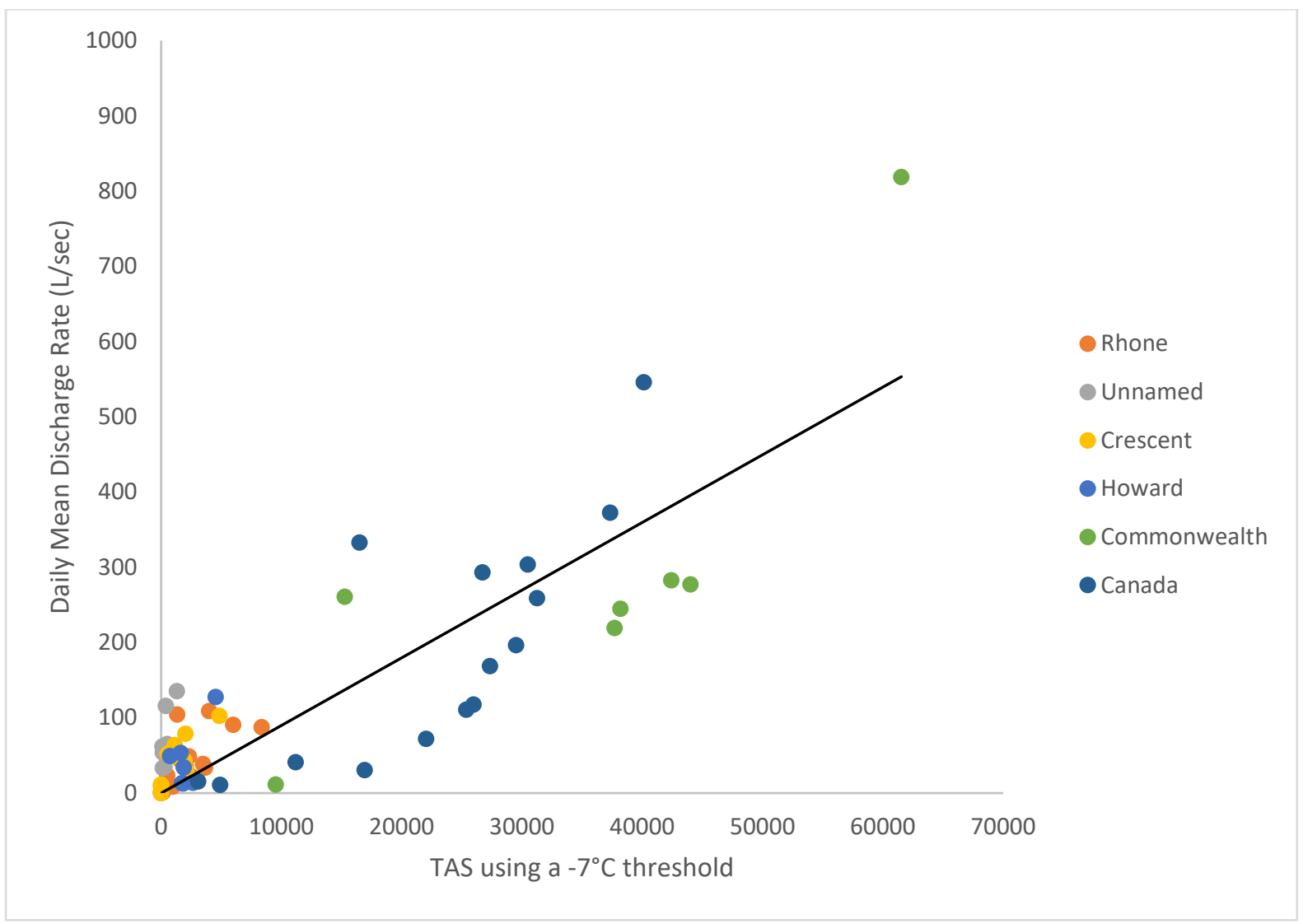


Figure 3: Regression between TAS at $-7^{\circ} \mathrm{C}$ threshold and mean daily discharge for all measured streams $\left(r^{2}=0.72\right.$, forced zero intercept, coefficient $\left.=0.0089, R M S=74.1\right)$

Using the coefficient from Figure 3, it is possible to calculate the daily mean discharge rate for a given pixel temperature. If there is only one pixel and the surface temperature is minus $6^{\circ} \mathrm{C}$, then the TAS value would be 1 , and therefore the daily mean discharge would be 0.0089 $\mathrm{L} / \mathrm{sec}$. Given that the pixel size is $30 \mathrm{~m}^{2}$, the number of pixel per ha is 11.1 . The mean daily flow rate is therefore $0.099 \mathrm{~L} / \mathrm{sec}$ for a hectare of glacier that is $-6^{\circ} \mathrm{C}$. The flow rate per hectare for any given surface temperature below zero can therefore be calculated, and is shown in Figure 4. The equation for this model is:

Daily mean discharge $(\mathrm{l} / \mathrm{s})$ for a hectare of ice $=0.099 \times\left(\operatorname{LST}^{0} \mathrm{C}+0.7\right)$ - for temperatures between $-7^{0} \mathrm{C}$ and $0^{0} \mathrm{C}$.

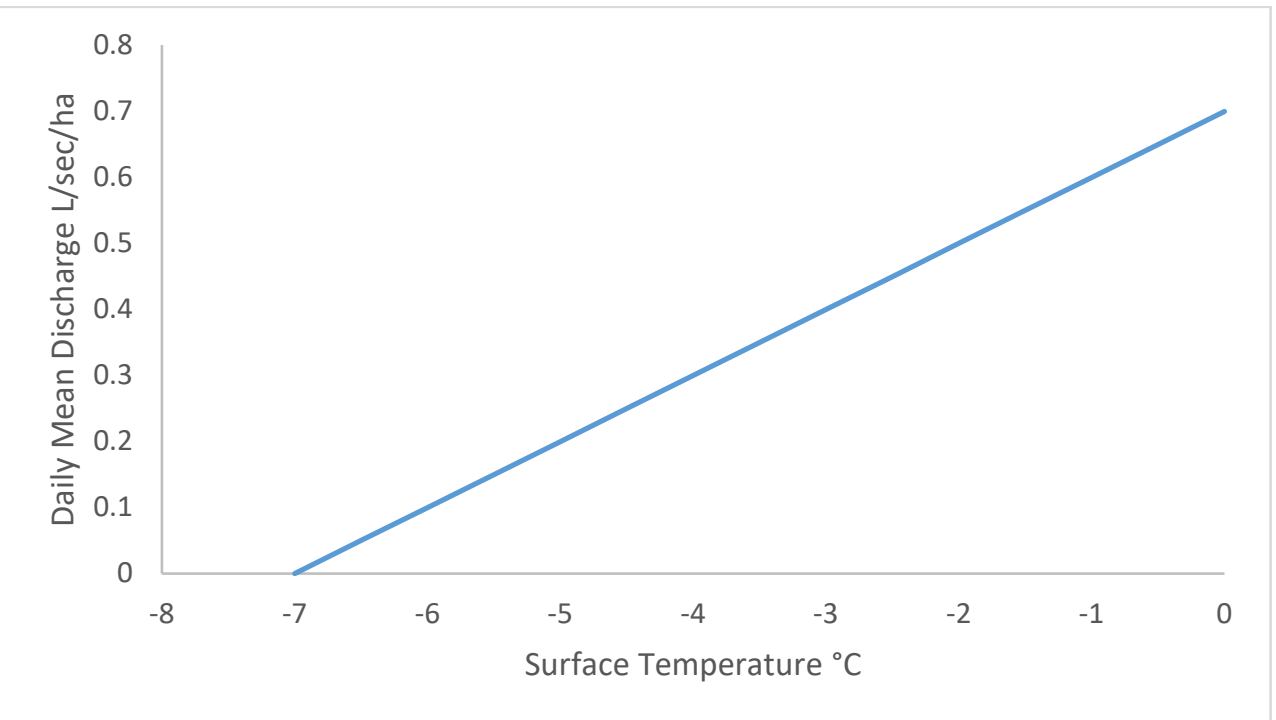

Figure 4: Melt rate for given glacier surface temperatures.

\section{MODIS Seasonal Model}

Figure 5 shows the MODIS seasonal (December-January) model using a seasonal average daily mean TAS and a temperature threshold of $-7^{\circ} \mathrm{C}$. The MODIS seasonal average daily mean TAS figures differ from the Landsat TAS figures because of the difference in pixel size. The Landsat pixels are smaller so more pixels are being summed. Due to the large catchment size of the Onyx River (Wright Valley), five outliers dominate the model. These 
outliers were identified as having a high leverage using Cook’s Distance (Cook, 1977) and were removed from the subsequent results of the seasonal models. The outliers that were removed were the following Wright Valley seasons: 2008-2009, 2004-2005, 2010-2011, 2011-2012, and 2013-2014.

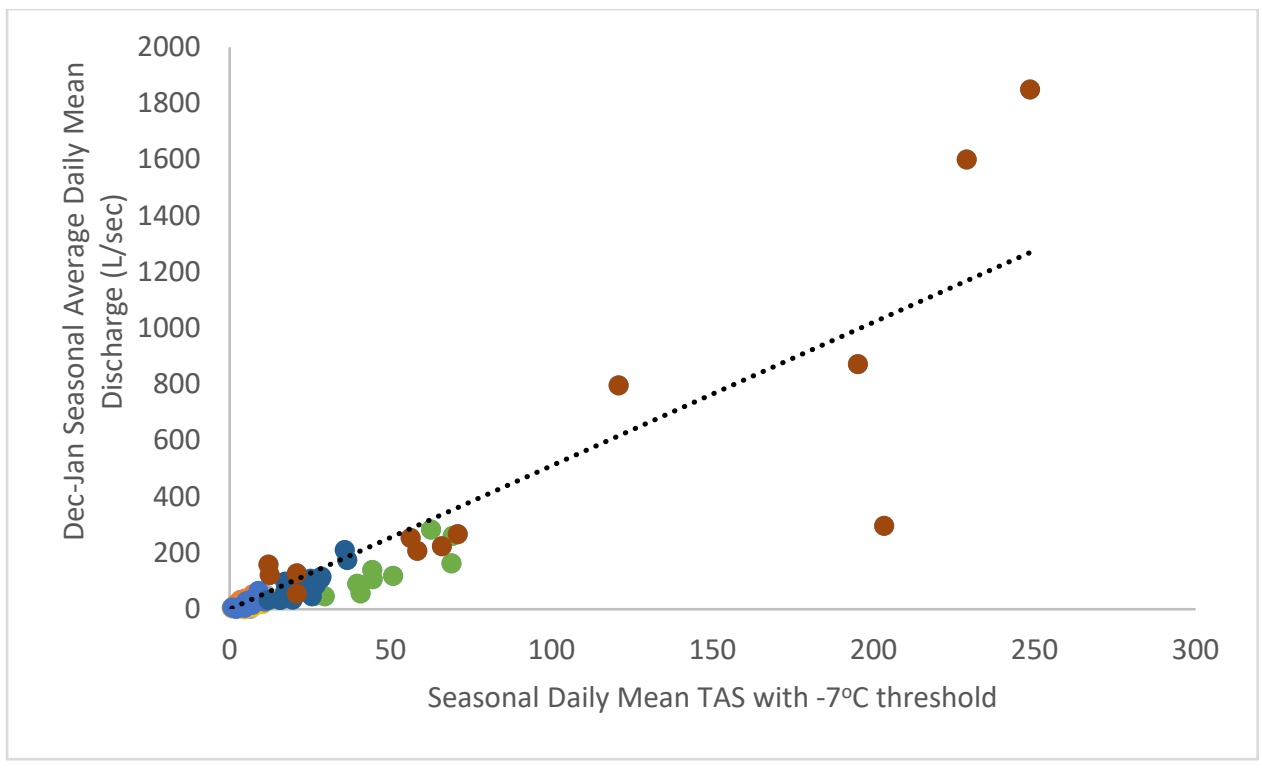

Figure 5. MODIS seasonal (December-January) regression model using seasonal mean discharge and seasonal daily mean TAS $\left(-7^{\circ} \mathrm{C}\right.$ threshold) with outliers and forced zero $\left(r^{2}=0.8\right.$, RMSE $=31.87 \mathrm{~L} / \mathrm{sec}$ and coefficient $=5.1$, $)$

Table 3 shows the OLS regression results for the MODIS seasonal average daily mean TAS against seasonal average daily mean discharge (outliers removed and forced zero) and compares the different season definitions and the temperature threshold. For the DecemberJanuary melt period, the most suitable model is the mean TAS model using a temperature thresholds of $-7^{\circ} \mathrm{C}$, which has $\mathrm{r}^{2}$ of 0.791 . For the November-February melt period, the seasonal mean TAS $-8^{\circ} \mathrm{C}$ model showed a slightly stronger $\mathrm{r}^{2}(0.798)$ than the $-7^{\circ} \mathrm{C}$ model. Figure 6 shows the OLS regression between the seasonal December-January mean TAS $-7^{\circ} \mathrm{C}$ and the December-January mean daily discharge, which has a coefficient of 3.4. Using this coefficient and scaling the MODIS pixel to one hectare (dividing by 100), the equation for seasonal mean daily discharge (December-January) is:

Seasonal Mean Daily Discharge (l/s) for a hectare of ice $=0.034$ x (seasonal daily mean LST ${ }^{0} \mathrm{C}+0.7$ ) - for temperatures between $-7^{0} \mathrm{C}$ and $0{ }^{0} \mathrm{C}$. 


\begin{tabular}{lrrrrrrrr}
\hline & \multicolumn{8}{c}{ Temperature Threshold $\left({ }^{\circ} \mathrm{C}\right)$} \\
\hline & -10 & -9 & -8 & -7 & -6 & -5 & -4 & -3 \\
\hline $\begin{array}{l}\text { December-January } \\
\begin{array}{l}\text { November- } \\
\text { February }\end{array}\end{array}$ & 0.647 & 0.714 & 0.786 & 0.791 & 0.637 & 0.463 & 0.391 & 0.374 \\
\hline
\end{tabular}

Table 3. TAS against seasonal mean daily discharge rate $\mathbf{r}^{2}$ values for all glacier zones.

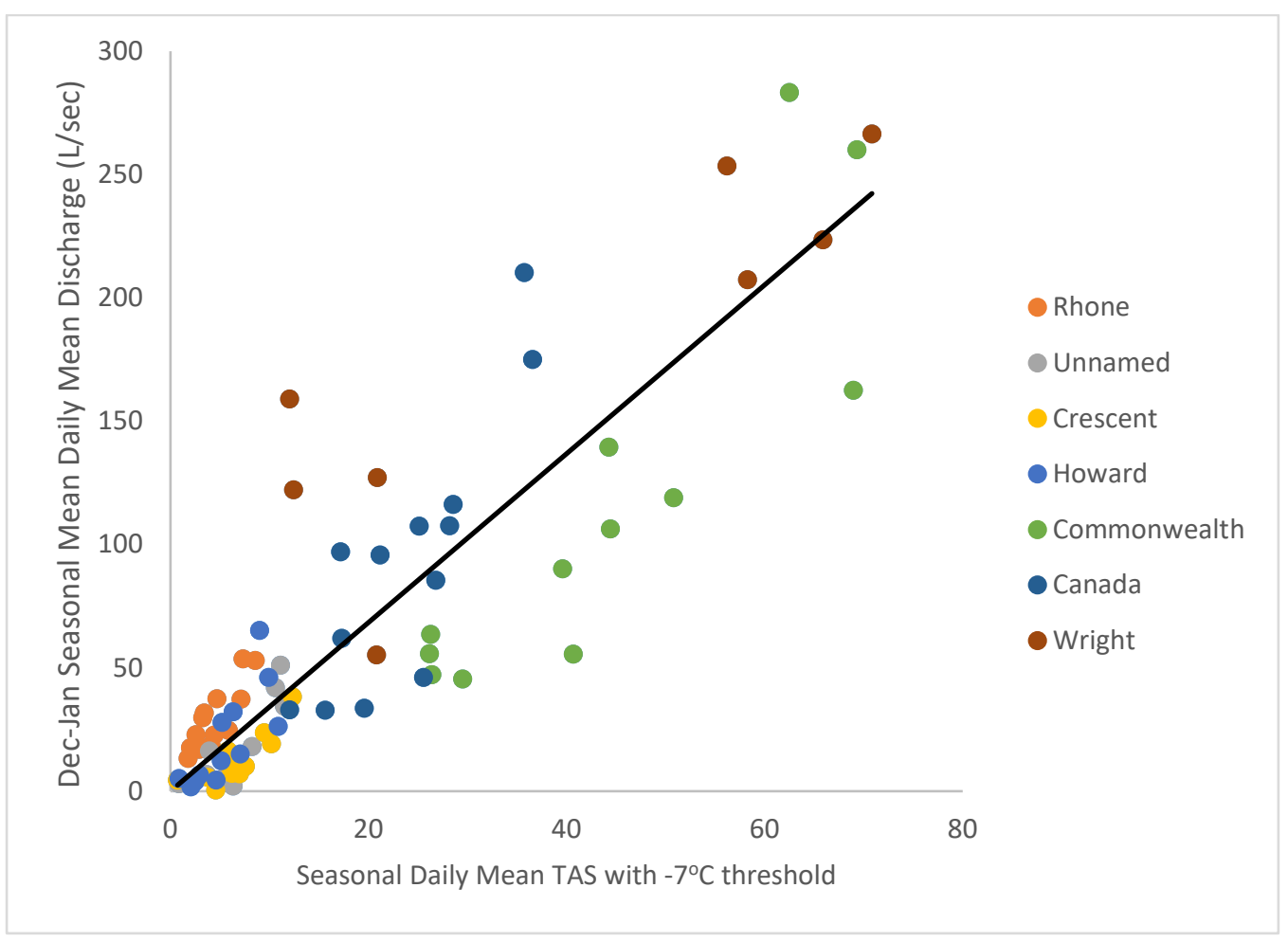

Figure 6: MODIS seasonal (December-January) regression model using seasonal daily mean discharge and seasonal daily mean TAS $\left(-7^{\circ} \mathrm{C}\right.$ threshold) without outliers and forced zero $\left(r^{2}=0.791, R M S E=31.87 \mathrm{~L} / \mathrm{sec}\right.$, and coefficient $\left.=3.4\right)$.

\section{Application on melt model to a Ross Sea Regional Wetness model}

Figure 7 shows the mean daily summer season surface temperature (Dec-Jan) for the Ross Sea Region. Using the seasonal TAS model provided in Figure 6, the meltwater produced from each snow / ice covered area can be estimated. How this meltwater flows over the landscape and accumulates can be modelled (see Figure 8) using the "accumulation" function in ArcGIS. The wetness can then be estimated using the CTI (Compound Terrain Index) described previously. Figure 9 shows the results of this. 


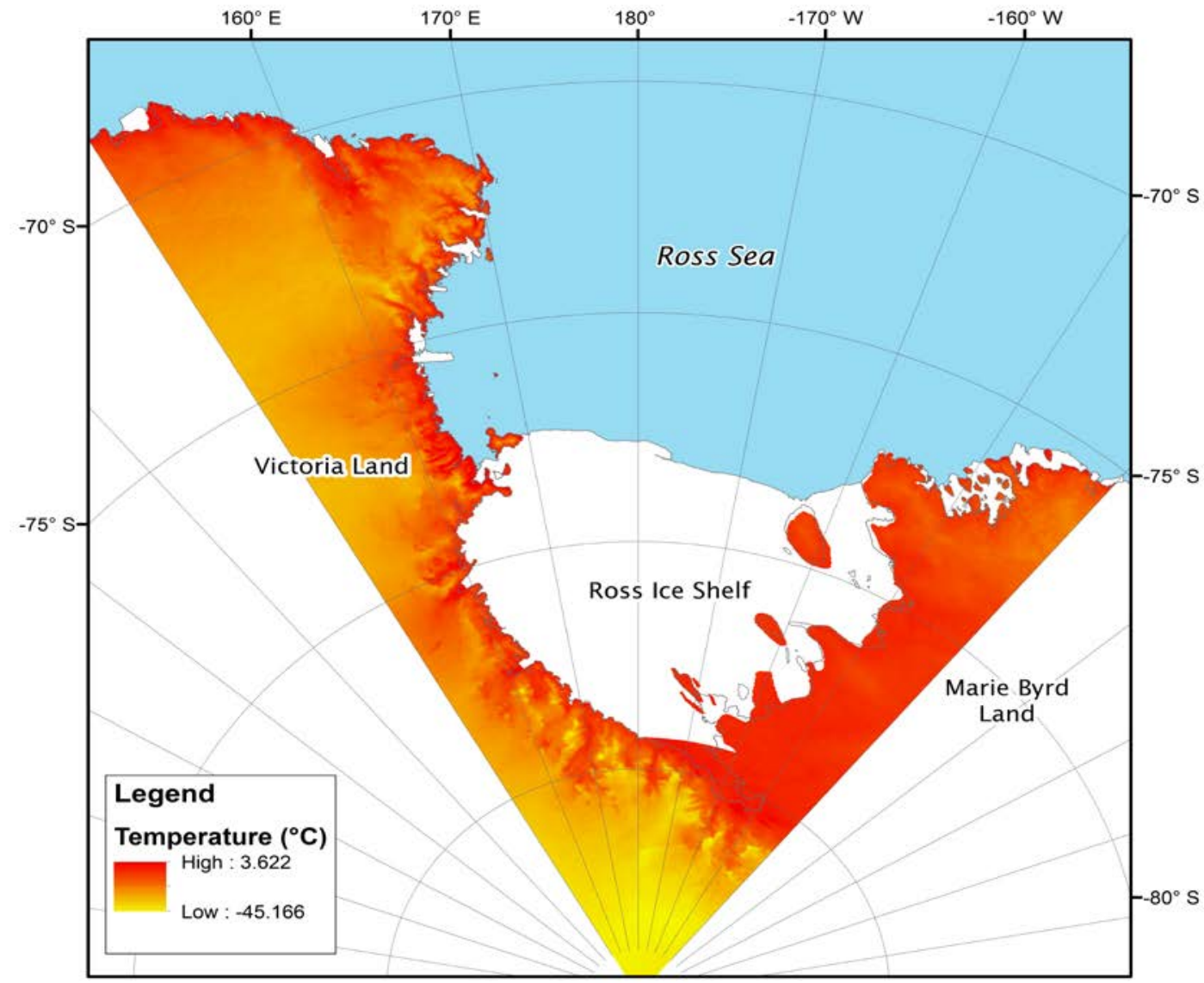

Figure 7: Ross Sea Region mean daily summer season (Dec-Jan) surface temperature using 2002 to 2016 MODIS images. 


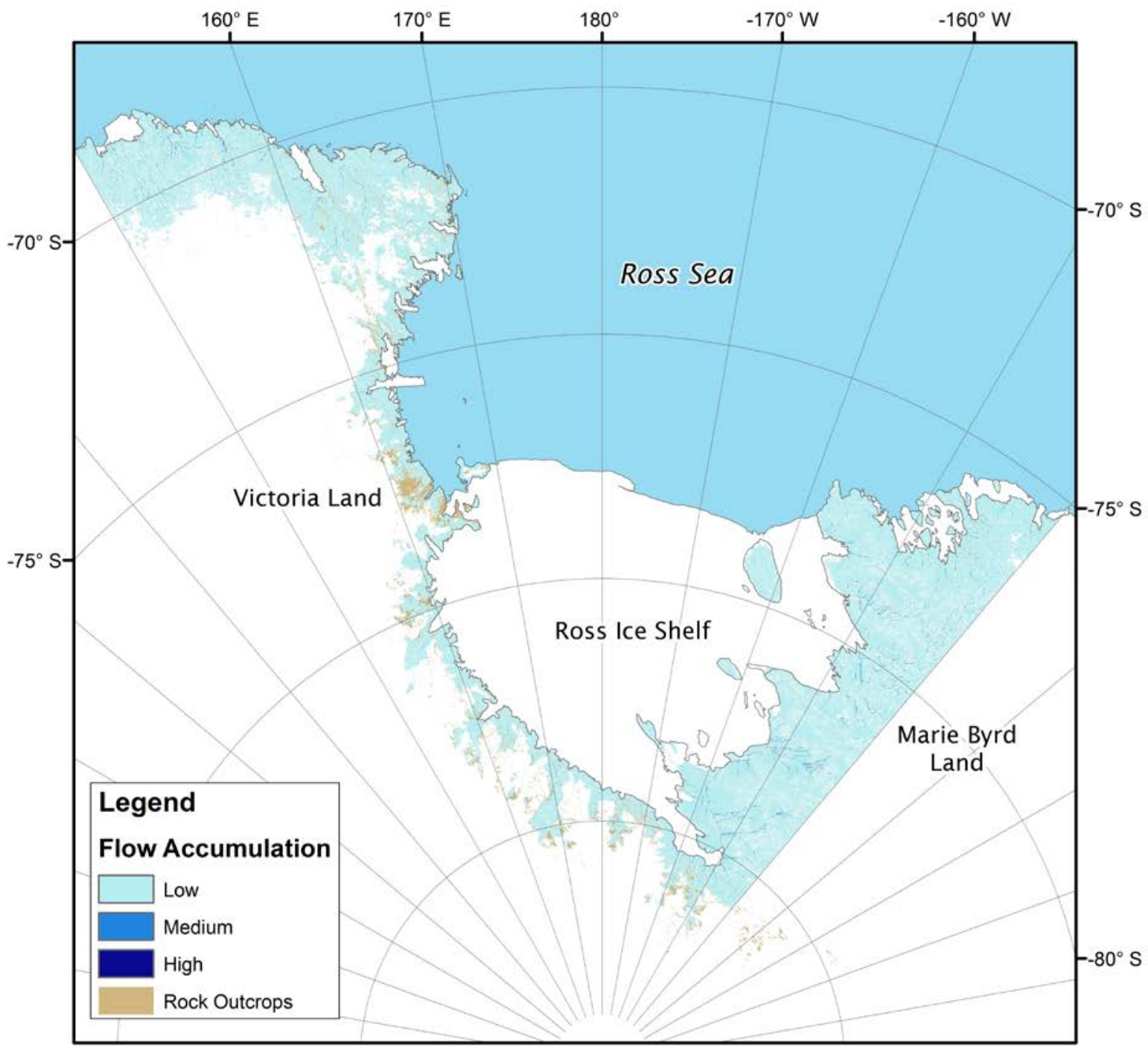

Figure 8: Ross Sea Region Mean Seasonal Flow Accumulation (Dec-Jan) 


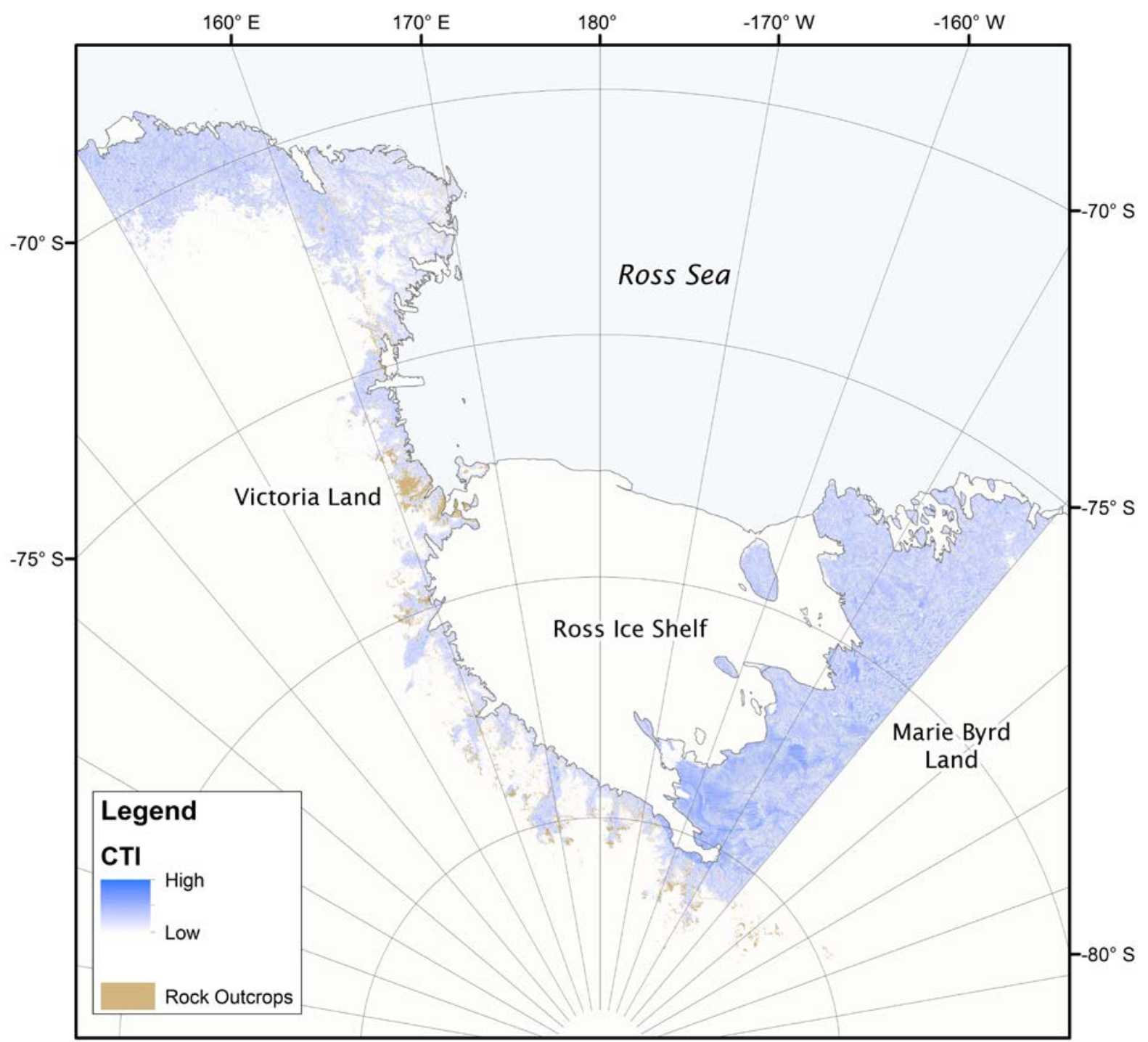

Figure 9: Ross Sea Region Wetness Index (Dec-Jan) 


\section{Conclusion}

This research has demonstrated how satellite LST data can be used in conjunction with glacier stream discharge data to develop models for predicting glacier surface melt rate. Since satellite LST data are collected globally and frequently (several times per day), these models potentially have a wide range of applications for exploring the impacts of climate change. A wetness model for the Ross Sea Region was developed to demonstrate such an application. Compared to energy balance and air temperature methods, the use of satellite LST data for modelling ice melt of glaciers is simple and produces robust results. The LST satellite data provide extensive and continuous coverage across space and do not require complex spatial modelling to interpolate or calibrate for topography. The TAS model is simple because satellite LST includes the effect of elevation, aspect, and albedo. TAS showed a slight improvement over the TAI model. In theory, TAS should be more sensitive than TAI because it sums the magnitude of the difference in LST and the temperature threshold, rather than just counting the pixels above the temperature threshold. Future use of the TAS should consider standardising this measurement to one-hectare spatial units, to provide easy comparisons between studies.

This research substantiates Dana et al's (2002) conclusion that satellite LST has a close relationship with flow rates and is a good substitute for traditional energy balance models and air temperature degree-days. Our research has taken Dana et al's (2002) analysis further by using hundreds of LST images over several seasons and has confirmed that this relationship is strong. The $\mathrm{r}^{2}$ values are not as high as Dana et al's (2002) study because the latter was based on one day, while our research contended with the variability associated with multiyear data. Using multi-year data, we have been able to develop a generalised melt rate models of glacier surfaces calibrated for Landsat 8 and MODIS images.

The Landsat and MODIS models are separate and are calibrated for the time of day that the LST is collected. The Landsat LST data used in this study were captured around 0900 hrs and were compared with daily mean stream discharge rates. In the morning, the LST of glaciers will be colder than later in the day. Therefore, the model will have a higher than expected melt rate. The MODIS LST is an average of several readings during the day and is averaged over the season.

It is interesting to ask whether these models have general applicability and can be applied to other regions of the world or even other parts of Antarctica. As discussed above, the timing of 
the satellite overpass is important and for different places in the world the satellite overpass time will differ. This is more likely to affect the Landsat LST because of their relatively infrequent overpasses compared to MODIS. Many glacier melt rate models based on water flow meters are specific to particular glaciers because the ground water flow varies between these glacier sites. The McMurdo Dry Valleys glaciers have minimal groundwater flow and the ice melt is generated from just the glacier surfaces. Therefore, the models developed in this paper are in theory applicable to other glaciers around the world, if just the surface melt is of interest. It is difficult to validate the general applicability of the models developed in this research because only glaciers in the Arctic environments will be limited to only surface melt and it is unlikely that there have been other stream gauges that measure just the surface melt.

A model that just estimates surface melt has a use for understanding glaciers in temperate environments where the melting is both on the surface and subterranean. If the total melt is known for a particular glacier, then the model developed in this study can be used to estimate the surface melt. The subterranean melt can then be calculated using the difference between total and surface melt.

As demonstrated in this study, melt rate can be used to predict wetness. Since this model uses LST, then if different climate change scenarios are presented as LST changes, then changes to melt rates and runoff can be modelled and used to show how the wetness of terrestrial habitats will change. As shown by the MODIS model, the discharge rate per hectare varies between 0.051 times the seasonal mean LST and 0.034 times the seasonal mean LST, depending on whether the outliers are included or excluded. This variation is significant but at least these figures provide an initial estimate. Additional research is required to further validate these multipliers. The main goal of this research is to demonstrate a method, rather than provide a definitive model.

An unexpected large wet area to the southwest of the Ross Ice Shelf (see Figure 9) has been estimated from this modelling. This requires further investigation and demonstrates the useful of these satellite models for large remote areas. The LST data for this area appears to be accurate. The low elevation of this area and extensive expanse of low angle ice / snow may be the reason for this high level of wetness accumulation. This study excluded the actual Ross Ice Shelf because the MODIS LST data products were only available for land area. It would be worthwhile analysing the Ross Ice Shelf as there are likely to be large areas of water accumulation during summers, and the stability of large ice shelves is of particular interest. 
The model also shows reasonable flow accumulations in the Marble Point region because of the melt from the large Wilson Piedmont Glacier that flows into this region. A biological response from increased water availability is expected and this will be interesting to monitor. Given the close proximity of US and New Zealand research bases to this region, the establishment of vegetation monitoring sites in this region would be practical.

More research is also required to fully understand extreme melting events in Antarctica. The outlier points in Figure 5, which are all associated with the larger Wright Valley catchment, show that there are seasons when a large amount of melting occurs, and there are historical records of large floods (Chinn and Mason, 2015). These outliers fit approximately with the linear model calculated for this research. It is interesting that the relationship between TAS and melt rate is linear. The melting of Antarctic glaciers may not be linear with predicted climate change scenarios because the topography of Antarctica is not distributed evenly. With warmer temperatures more areas at high elevation will start melting. Since there are large areas of high elevation ice in Antarctica, the melt rate will not be linear.

It would be useful to research the relationship between TAS and melt rate using a physical scale model of ice. A literature and internet search did not find any records of such research. With a scale mode, it would be possible to explore what happens with extreme melting when the LST is close to $0^{0} \mathrm{C}$. Given the usefulness of satellite LST for ice melt, scale model research on LST and ice melt would assist with validation. This is beyond the skills of the authors who specialise in geospatial modelling.

The analysis presented in this research involved a considerable amount of satellite data and computer processing. This research has demonstrated applications of "Big Data” and the valuable contribution satellite archives, such as developed by NASA, provide for science. This research also relied on the hydrological data collected by the U.S. Long Term Ecological Research programme in the McMurdo Dry Valleys This research demonstrates the importance of this data, and sharing of this data. Antarctica is an expensive place to complete fieldwork, and the use of satellite based remote sensing and collaborative sharing of data between national programmes is proving to be an efficient method for analysing the unique Antarctic environment.

\section{References}


Adiguzel, F., Cetin, M., Kaya, E., Simsek, M., Gungor, S., \& Sert, B. (2019). Defining suitable areas for bioclimatic comfort for landscape planning and landscape management in Hatay, Turkey. Theor Appl Climatol 139, 1493-1503, doi: 10.1007/s00704-019-03065-7.

Braithwaite, R. J. (1995). Positive degree-day factors for ablation on the Greenland ice sheet studied by energy-balance modelling. Journal of Glaciology, 41(137), 153-160.

Barrand, N.E., Vaughan, D. G., Steiner, N., Tedesco, M., Kuipers, M. P., van den Broeke, M. R., \& Hosking, J. S. (2013). Trends in Antarctic Peninsula surface melting conditionsfrom observations and regional climate modeling. Journal Of Geophysical Research: Earth Surface, 118, 315-330, doi:10.1029/2012JF002559.

Chinn T.J. (1981). Hydrology and climate in the Ross Sea area. Journal of the Royal Society of New Zealand 11, 373-386.

Chinn, T., \& Mason, P. (2015). The first 25 years of the hydrology of the Onyx River,Wright Valley, Dry Valleys, Antarctica, Polar Record, doi:10.1017/S0032247415000212

Cook, R. D. (1977). Detection of Influential Observations in Linear Regression. Technometrics. American Statistical Association. 19, 15-18. doi:10.2307/1268249.

Costi, J., Arigony-Neto, J., Braun, M., Mavlyudov, B., Barrand, N. E., Da Silva, A. B., Marques, W. C., \& Simões, J. C. (2018). Estimating surface melt and runoff on the Antarctic Peninsula using ERA-Interim reanalysis data. Antarctic Science 30, 379-393. doi:10.1017/S0954102018000391.

Dana, G. L., Davis, R. E., Fountain, A. G., \& Wharton, R. A. (2002). Satellite-derived indices of stream discharge in Taylor Valley, Antarctica. Hydrological Processes, 16(8), 1603-1616. doi:10.1002/hyp.1024

Ebnet, A. F., Fountain, A. G., Nylen, T. H., McKnight, D. M., \& Jaros, C. L. (2005). A temperature-index model of stream flow at below-freezing temperatures in Taylor Valley, Antarctica. Annals of Glaciology, 40(1), 76-82. doi:10.3189/172756405781813519

Etourneau, J., Giovanni, S., Xavier, C., Didier, S., Verónica, W., Loïc, B., Marie-Noëlle, H., Stefan, S., Sinninghe, D. J.S., Hugues, G., Carlota, E., Julien, C., Guillaume, M., \& Jung- 
Hyun, K. (2019). Ocean temperature impact on ice shelf extent in the eastern Antarctic Peninsula. Nature communications. 10 (1), 304.

Fountain, A. G., Lyons, W. B., Burkins, M. B., Dana, G. L., Doran, P. T., Lewis, K. J., . . Virginia, R. A. (1999). Physical Controls on the Taylor Valley Ecosystem, Antarctica. BioScience, 49(12), 961-971.

Gooseff, M. N., Barrett, J. E., Doran, P. T., Fountain, A. G., Lyons, W. B., Parsons, A. N., \& Wall, D. H. (2003). Snow-Patch Influence on Soil Biogeochemical Processes and Invertebrate Distribution in the McMurdo Dry Valleys, Antarctica. Arctic, Antarctic, and Alpine Research, 35(1), 91-99. doi:10.2307/1552333

Gooseff, M. N., McKnight, D. M., Doran, P., Fountain, A. G., \& Lyons, W. B. (2011). Hydrological Connectivity of the Landscape of the McMurdo Dry Valleys, Antarctica. Geography Compass, 5(9), 666-681. doi:10.1111/j.1749-8198.2011.00445.x

Hock, R. (2003). Temperature index melt modelling in mountain areas. Journal of Hydrology, 282(1-4), 104-115. doi:http://dx.doi.org/10.1016/S0022-1694(03)00257-9 Hock, R. (2005). Glacier melt: a review of processes and their modelling. Progress in Physical Geography, 29(3), 362-391. doi:10.1191/0309133305pp453ra

Hoffman, M. J., Fountain, A. G., \& Liston, G. E. (2008). Surface energy balance and melt thresholds over 11 years at Taylor Glacier, Antarctica. Journal of Geophysical Research: Earth Surface, 113(F4), F04014. doi:10.1029/2008jf001029

Hoffman, M. J., Fountain, A. G., \& Liston, G. E. (2014). Near-surface internal melting: a substantial mass loss on Antarctic Dry Valley glaciers. Journal of Glaciology, 60(220), 361374. doi:10.3189/2014JoG13J095

Hoffman, M. J., Fountain, A. G., \& Liston, G. E. (2016). Distributed modeling of ablation (1996-2011) and climate sensitivity on the glaciers of Taylor Valley, Antarctica. Journal of Glaciology, 62(232), 215-229. doi:10.1017/jog.2015.2

Kennedy, A. D. (1993). Water as a Limiting Factor in the Antarctic Terrestrial Environment: A Biogeographical Synthesis. Arctic and Alpine Research, 25(4), 308-315. doi:10.2307/1551914

Kingslake, K., Ely, J. C., Das, I. \& Bell, R. E, (2017). Widespread movement of meltwater onto and across Antarctic ice shelves. Nature Letter VO L 544 doi:10.1038/nature22049 
Lewis, K. J., Fountain, A. G., \& Dana, G. L. (1998). Surface energy balance and meltwater production for a Dry Valley glacier, Taylor Valley, Antarctica. Annals of Glaciology, 27, 603-609.

MacDonell, S. A., Fitzsimons, S. J., \& Mölg, T. (2013). Seasonal sediment fluxes forcing supraglacial melting on the Wright Lower Glacier, McMurdo Dry Valleys, Antarctica. Hydrological Processes, 27(22), 3192-3207. doi:10.1002/hyp.9444 McKnight, D. M., Niyogi, D. K., Alger, A. S., Bomblies, A., Conovitz, P. A., \& Tate, C. M. (1999). Dry Valley Streams in Antarctica: Ecosystems Waiting for Water. BioScience, 49(12), 985-995. doi:10.1525/bisi.1999.49.12.985

McMurdo Dry Valleys Long Term Ecological Research (2019). GIS data sets. http://mcm.lternet.edu/gis-data

Stichbury, G., Brabyn, L., Green, T. G. A., \& Cary, C. (2011). Spatial modelling of wetness for the Antarctic Dry Valleys. Polar Research, 30(SUPPL.1). 